\title{
The Global Volatile Signature of Veal via Solid-phase Microextraction and Gas Chromatography-mass Spectrometry
}

\author{
Jinmei Wei, Kun Wan, Yuzhu Luo*, and Li Zhang \\ Gansu Agricultural University, Gansu Key Laboratory of Herbivorous Animal Biotechnology, \\ Lanzhou 730070, China
}

\begin{abstract}
The volatile composition of veal has yet to be reported and is one of the important factors determining meat character and quality. To identify the most important aroma compounds in veal from Holstein bull calves fed one of three diets, samples were subjected to solid-phase microextraction (SPME) combined with gas chromatography-quadrupole mass spectrometry (GC-MS). Most of the important odorants were aldehydes and alcohols. For group A (veal calves fed entirely on milk for $90 \mathrm{~d}$ before slaughter), the most abundant compound class was the aldehydes (52.231\%), while that was alcohols $(26.260 \%)$ in group C (veal calves fed starter diet for at least $60 \mathrm{~d}$ before slaughter). In both classes the absolute percentages of the volatile compounds in veal were different indicating that the veal diet significantly $(p<0.05)$ affected headspace volatile composition in veal as determined by principal component analysis (PCA). Twenty three volatile compounds showed significance by using a partial least-squared discriminate analysis (PLS-DA) (VIP $>1$ ). The establishment of the global volatile signature of veal may be a useful tool to define the beef diet that improves the organoleptic characteristics of the meat and consequently impacts both its taste and economic value.
\end{abstract}

Keywords: veal, volatile, SPME-GC-MS, PCA, PLS-DA

\section{Introduction}

Veal is more tender and juicy than fully aged beef, yet a detailed characterization of its volatile components is currently missing in the literature (Mao et al., 2011). The volatile composition of meat is one of the most important factors that determine its taste, character, and quality (Gorraiz et al., 2002; Tan et al., 2004). Consumers continue to demand high-quality and consistent meats at a reasonable price (Stetzer et al., 2008). The sensory traits that mostly affect consumer acceptability of beef are tenderness and flavor (Robbins et al., 2003a, b). To date, more than 1000 volatile compounds contributing to the odor of cooked meat have been identified (Lee et al., 2012; Rivas-Cañedo et al., 2009; Wang et al., 2006; Watkins et al., 2012). As with many food products the aroma of beef is influenced by hundreds of volatile organic compounds (VOCs) and semi-volatile organic compounds (SVOCs) belonging to different chemical families includ-

\footnotetext{
*Corresponding author: Yuzhu Luo, Gansu Agricultural University, Gansu Key Laboratory of Herbivorous Animal Biotechnology, Lanzhou 730070, China. Tel: +86-931-7632-483. Fax: +86-931-7632-483. E-mail: yuzhuluo@yeah.net
}

ing ketones, esters, aldehydes, alcohols, acids, carbonyl compounds, sulphur compounds, and many others (Moon et al., 2006; Tan et al., 2004).

The Maillard reaction, thiamin degradation, and lipid oxidation are the main reactions that generate flavor when meat is cooked (Calkins et al., 2007; Koutsidis et al., 2008a, b; Varavinit et al., 2000). It showed that benzene and furan compounds were stewed beef flavor components (Shi et al., 2011) and 4-hydroxy-2, 5-dimethyl-3 $(2 \mathrm{H})$-furanone and 4-hydroxyl-5-methyl-3 $(2 \mathrm{H})$-furanone were very important for high impact beef flavor (Guth et al., 1994). Then, many of the VOCs and SVOCs are generally present in trace amounts (from several $\mathrm{mg} / \mathrm{L}$ to a few ng/L, or even less), which means that an effective extraction technique to enrich or concentrate the analytes as well as a sensitive detection scheme are required for proper measurement. Previously, several methodologies involving static headspace analysis (Guth et al., 1994), purge and trap (Insausti et al., 2005), distillation/extraction techniques (Gasser et al., 1988), and concentration on solidphase supports (solid-phase extraction-SPE) followed by analysis using gas chromatography-mass spectrometry (GC-MS) (Ruiz et al., 1998) have been widely proposed and used to establish the aroma profile of beef. An artifi- 
cial nose (an electronic nose) was used to give an objective basis for odor and flavor identification that correlates with human sensory experience (Wilkes et al., 2000).

Nevertheless, these methodologies have important limitations including their relatively low reproducibility, low selectivity, and loss of analytes during concentration. Additionally, they require the use of toxic and expensive solvents, and are time consuming and labor-intensive. More recently, solvent-free methodologies that overcome these drawbacks have been widely used, such as solidphase microextraction (SPME) (Watkins et al., 2012). The SPME methodology is very suitable for organic analytical chemistry because it is a fast, simple, and sensitive procedure that eliminates the use of organic solvents and combines sampling, extraction, and concentration into a single step, substantially shortening analysis time. For these reasons, there are many applications of SPME in food analysis. While this approach has been used to analyze the volatile composition of beef, to the best of our knowledge, there were not the documents which determined the volatile composition in veal, yet. This study reports the development of a reliable and solvent-free SPME-GC-MS methodology to establish the global volatile signature of veal. "Unsupervised" principal component analysis (PCA) and "Supervised" partial least-squared discriminate analysis (PLS-DA) were used to process the GC-MS data to determine which volatile compounds show significance in veal.

\section{Materials and Methods}

\section{Materials}

The divinylbenzene/Carboxen $\AA /$ polydimethylsilicone (50/ $30 \mu \mathrm{m}$ DVB/CAR/PDMS) SPME fiber (Cat. no. 57329$\mathrm{U})$ glass vials were purchased from Supelco, Inc. (Australia). The SPME fiber was pre-conditioned at $250^{\circ} \mathrm{C}$ for 1 $\mathrm{h}$ according to the manufacturer's recommendation.

\section{Experimental animals and samples}

Fifteen 2-3 d old Holstein bull calves with the birth weight from 35.01 to $37.77 \mathrm{~kg}$ (mean live weight [LW] = $36.14 \mathrm{~kg}$ ) were selected, pre-fed entirely on milk for 5-
$8 \mathrm{~d}$ and randomly divided into three groups: (A) whole milk feeding group; (B) quantitative feeding group of whole milk and calf starter diet; (C) ad libitum feeding group of whole milk and calf starter diet. Each group contained 5 animals. The quantities of milk and starter were offered at $8 \% \mathrm{LW}$ of calves (the exact experimental quantity for milk and starter diet was shown in Table 1). Whole milk was purchased from the dairy farm of Gansu Agricultural University for daily feeding of the calves. Calf no. 1 pellet diet was purchased from the Boya Feed Co., Ltd, China. Calf no. 1 pellet diet contained (as fed basis): corn grain $(460 \mathrm{~g} / \mathrm{kg})$, wheat bran $(150 \mathrm{~g} / \mathrm{kg})$, whey powder $(50 \mathrm{~g} / \mathrm{kg})$, soybean meal $(250 \mathrm{~g} / \mathrm{kg})$, molasses $(55 \mathrm{~g} / \mathrm{kg})$, CaHPO4(10 g/kg) mineral/vitamin premix (20 g/kg), and limestone $(5 \mathrm{~g} / \mathrm{kg})$.

All animals were slaughtered after $90 \mathrm{~d}$. A hundred grams of fresh veal longissimus dorsi muscle where the branched-chain fatty acids are present at subthreshold odour levels (Brennand et al., 1992) were collected, homogenized, mixed together in each feeding group. Samples were stored at $-18^{\circ} \mathrm{C}$ for later use.

This study was performed in the dairy division of the animal science training center at Gansu Agricultural University, Lanzhou, China. Experimental procedures and animal holding facilities respected the relevant animal protection legislation of China (Regulations on the management of laboratory animal 1988, State Scientific and Technological Commission of the People's Republic of China; Measures for the management of animal quarantine 2010, Ministry of Agriculture of the People's Republic of China). Animals were slaughtered at the experimental abattoir of Gansu Agricultural University (Lanzhou, China) by exsanguination after stunning with a cartridge-fired captive bolt stunner.

\section{SPME procedure}

The samples were removed from the freezer and allowed to reach room temperature prior to analysis. A $10 \mathrm{~g}$ sample was placed in a vial to which $10 \mathrm{~g}$ of sodium chloride $(\mathrm{NaCl})$ was added. $\mathrm{NaCl}$ had salting-out effect, in order to increase the organic volatile (Shi et al., 2011; Wei et al., 2011). The vials and their contents were pre-heated at 90

Table 1. Grouping of Holstein bull calves and daily average feeding per animal

\begin{tabular}{cccccccc}
\hline \hline \multirow{2}{*}{ Group } & \multirow{2}{*}{ No. of calves } & \multicolumn{2}{c}{ 1st month } & \multicolumn{2}{c}{ 2nd month } & \multicolumn{2}{c}{ 3rd month } \\
\cline { 2 - 8 } & & Milk/kg & Starter $/ \mathrm{kg}$ & Milk/kg & Starter $/ \mathrm{kg}$ & Milk/kg & Starter/kg \\
\hline $\mathrm{A}$ & 5 & 4.35 & - & 6.35 & - & 9.68 & - \\
$\mathrm{B}$ & 5 & 4.25 & - & 5.14 & 0.32 & 6.11 & 1.85 \\
$\mathrm{C}$ & 5 & 4.30 & - & 5.36 & 0.48 & ad libitum & ad libitum \\
\hline
\end{tabular}


$\pm 1^{\circ} \mathrm{C}$ for $60 \mathrm{~min}$ in a thermostatted bath. Then the temperature was adjusted to $60 \pm 1^{\circ} \mathrm{C}$ prior to the insertion of the DVB/CAR/PDMS SPME fiber into the headspace where it was held for $40 \mathrm{~min}$ (Vasta et al., 2007). The fiber was then withdrawn and manually inserted into the GC injector to allow the adsorbed compounds to be transferred to the analytical column. The fiber was held in the injector for $15 \mathrm{~min}$.

\section{GC-MS analysis}

The volatile compounds were separated using an OV$1701 \mathrm{MS}$ fused silica capillary column $(60 \mathrm{~m} \times 0.25 \mathrm{~mm}$ i.d. $\times 0.25 \mu \mathrm{m}$ film thickness, Chromatographic Technology R\&D, Lanzhou Institute of Chemical Physics, Chinese Academy of Sciences) in an Agilent GC-MS system (Agilent Technologies, USA) utilizing a model $6890 \mathrm{~N}$ gas chromatograph and a model $5973 \mathrm{~N}$ mass selective detector. The GC oven temperature was initially held at $50^{\circ} \mathrm{C}$ for 1 min, increased at a rate of $3.5^{\circ} \mathrm{C} / \mathrm{min}$ to $220^{\circ} \mathrm{C}$ where it was held for a further $20 \mathrm{~min}$. For SPME, the injector, heated at $260^{\circ} \mathrm{C}$, was held in the splitless mode for the first $2 \mathrm{~min}$ of the analysis and then in the split mode (20:1) for the remainder of the analysis. The SPME fiber remained in the injector for $15 \mathrm{~min}$ to clean the fiber with a solvent delay time of $3.5 \mathrm{~min}$. Helium was used as the carrier gas with a constant flow rate of $1.0 \mathrm{~mL} / \mathrm{min}$. The MS was operated in electron ionisation mode $(70 \mathrm{eV})$ and data was acquired in full scan mode for range of 30 to $550 \mathrm{~m} / \mathrm{z}$. The temperature of the source and the detector were 150 and $230^{\circ} \mathrm{C}$, respectively, while the MS transfer line was $280^{\circ} \mathrm{C}$.

\section{Multivariate data analysis and data processing}

Compounds were identified by comparing the mass spectra to those found in the NIST 05 mass spectral library (NIST, 2005 software, Mass Spectral Search Program V.2.0 d; NIST 2005, USA) by the match and the relative match (R. match) 80\% (Qi et al., 2010). The GC peak areas for each compound were calculated using the total ion chromatogram, assuming a relative response factor of one for each compound. The results of the volatile analysis were reported as percentages, representing the proportion of each identified peak to the total area of identified peaks in each chromatogram.

The resulting datasets were then imported into SIMCAP 11.5 (Umetrics, Sweden) for multivariate statistical analyses. All imported data were Pareto-scaled for the multivariate analysis. First, principal components analysis (PCA) was conducted on the spectra of veal samples to discern the presence of inherent similarities in spectral profiles. Next, a PLS-DA was used to maximize covariance between the measured data (peak intensities in GC-MS spectra, $\mathrm{X}$ matrix) and the response variable (predictive classifications, $\mathrm{Y}$ matrix) by searching for $\mathrm{X}$ variables that correlated with class membership and thus indicated that the response variable $\mathrm{Y}$ can be predicted from $\mathrm{X}$.

PLS-DA was also applied to the relative concentration data of assigned volatile compounds. The variable importance in the projection (VIP) plot was then used to identify which volatile compound contributed most to clustering or trends observed in the data.

\section{Statistical analyses}

The statistical analysis was conducted using SPSS 19 for Windows (SPSS Inc., IBM Corporation, USA). Oneway Analysis of Variance (ANOVA) was applied to test differences between groups (A, B and C) for all variables studied by VIP $>1$. Differences with a $p$-value of 0.05 were considered significant. Assays were performed in quintuplicate, and the results were expressed as mean \pm SD.

\section{Results and Discussion}

\section{Comparison of samples}

More than 125 compounds were detected from longissimus dorsi muscle of veal fed 3 different feeding treatment using SPME with GC-MS. Through comparison to the NIST spectral library, a total of 9 ketones, 16 aldehydes, 11 alcohols, 9 hydrocarbons and 9 other compounds were identified. Fourty seven of the 125 peaks gave a definitive match in group A. These peaks accounted for $92.71 \%$ of all the compounds. Similarly, 50 and 44 compounds were identified in group B and C; their content accounted for $96.05 \%$ and $76.91 \%$, respectively (Table 2 ).

Aldehydes, ketones, alcohols, and hydrocarbons were the four main classes of compounds identified in the veal samples. For group A, the most abundant compound class was the aldehydes (52.231\%), followed by the alcohols (20.890\%), hydrocarbons (5.296\%), and the ketones $(3.749 \%)$. A similar trend was observed with group B and $\mathrm{C}$, but the percentages of four classes were different. In group $\mathrm{B}$, the aldehydes, alcohols, hydrocarbons and the ketones were $49.631 \%, 22.558 \%, 6.308 \%$ and $3.053 \%$, respectively. They were $31.247 \%, 22.260 \%, 8.105 \%$ and $2.497 \%$ in group C, respectively. That is, the total GC peak area percentage content (\%) of the aldehydes was the highest in group A and lowest in group C. The ketones showed the same trend as the aldehydes. However, the alco- 
hols and hydrocarbons showed the opposite trend. The percentage content (\%) of alcohols was in the highest in group C and lowest in group A, and hydrocarbons' was as the same. It suggested that marked differences existed between the proportions of the extracted compounds by SPME that were common to three groups.

\section{PCA and PLS-DA}

Here, "Unsupervised" PCA and "Supervised" PLS-DA were used to process the GC-MS data. PCA and PLS-DA were used because they cope well with highly multivariate, noisy, collinear, and possibly incomplete data. PCA is an unsupervised pattern recognition method initially used

Table 2. Volatile compounds of muscle longissimus dorsi from veal fed different diets ${ }^{\mathrm{a}}$

\begin{tabular}{|c|c|c|c|c|c|c|}
\hline \multirow{2}{*}{$\begin{array}{c}\begin{array}{c}\text { Peak } \\
n\end{array} \\
\text { n }\end{array}$} & \multirow{2}{*}{$\begin{array}{l}\mathrm{RT}^{\mathrm{b}} \\
(\mathrm{min})\end{array}$} & \multirow{2}{*}{ Compounds } & \multirow{2}{*}{$\begin{array}{c}\text { Molecular } \\
\text { formula }\end{array}$} & \multicolumn{3}{|c|}{ 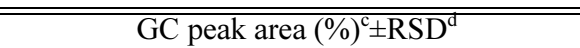 } \\
\hline & & & & A & $\mathrm{B}$ & $\mathrm{C}$ \\
\hline \multicolumn{7}{|c|}{ Ketones } \\
\hline 1 & 6.97 & 2-Butanone & $\mathrm{C}_{4} \mathrm{H}_{8} \mathrm{O}$ & - & - & $0.279 \pm 0.012$ \\
\hline 6 & 12.15 & 3-Hydroxy-2-Butanone & $\mathrm{C}_{4} \mathrm{H}_{8} \mathrm{O}_{2}$ & $0.295 \pm 0.007$ & $0.583 \pm 0.027$ & $0.262 \pm 0.0280$ \\
\hline 10 & 17.84 & 2-Heptanone & $\mathrm{C}_{7} \mathrm{H}_{14} \mathrm{O}$ & $0.878 \pm 0.069$ & $0.577 \pm 0.012$ & $0.539 \pm 0.031$ \\
\hline 18 & 22.41 & 2-Octanone & $\mathrm{C}_{8} \mathrm{H}_{16} \mathrm{O}$ & $0.566 \pm 0.109$ & $0.439 \pm 0.040$ & $0.409 \pm 0.010$ \\
\hline 24 & 26.88 & 2-Nonanone & $\mathrm{C}_{9} \mathrm{H}_{18} \mathrm{O}$ & $0.641 \pm 0.070$ & $0.282 \pm 0.015$ & $0.498 \pm 0.010$ \\
\hline 31 & 31.17 & 2-Decanone & $\mathrm{C}_{10} \mathrm{H}_{20} \mathrm{O}$ & $0.351 \pm 0.089$ & $0.192 \pm 0.005$ & - \\
\hline 44 & 42.01 & 3-(3-Hydroxy-1-Propenyl)-Cyclopentanone & $\mathrm{C}_{8} \mathrm{H}_{12} \mathrm{O}_{2}$ & $0.411 \pm 0.051$ & $0.544 \pm 0.021$ & - \\
\hline 46 & 42.48 & Dihydro-5-Propyl-2(3H)-Furanone & $\mathrm{C}_{7} \mathrm{H}_{12} \mathrm{O}_{2}$ & $0.336 \pm 0.025$ & $0.434 \pm 0.046$ & $0.510 \pm 0.012$ \\
\hline \multirow[t]{3}{*}{52} & 52.81 & Butylidene-1(3H)-Isobenzofuranone & $\mathrm{C}_{12} \mathrm{H}_{12} \mathrm{O}_{2}$ & $0.271 \pm 0.031$ & - & - \\
\hline & & Subtotal (GC peak area) & & $3.749 \pm 0.035$ & $3.053 \pm 0.017$ & $2.497 \pm 0.011$ \\
\hline & & Subtotal compounds number & & 8 & 7 & 6 \\
\hline \multicolumn{7}{|c|}{ Aldehydes } \\
\hline 3 & 9.58 & Pentanal & $\mathrm{C}_{5} \mathrm{H}_{10} \mathrm{O}$ & $0.940 \pm 0.049$ & $0.623 \pm 0.062$ & $0.326 \pm 0.022$ \\
\hline 8 & 13.56 & Hexanal & $\mathrm{C}_{6} \mathrm{H}_{12} \mathrm{O}$ & $17.665 \pm 0.393$ & $21.424 \pm 0.261$ & $10.158 \pm 0.145$ \\
\hline 11 & 18.07 & Heptanal & $\mathrm{C}_{7} \mathrm{H}_{14} \mathrm{O}$ & $4.632 \pm 0.252$ & $3.601 \pm 0.154$ & $2.647 \pm 0.088$ \\
\hline 12 & 18.28 & (Z)-4-Heptenal & $\mathrm{C}_{7} \mathrm{H}_{12} \mathrm{O}$ & $0.150 \pm 0.029$ & - & - \\
\hline 15 & 21.83 & (E)-2-Heptenal & $\mathrm{C}_{7} \mathrm{H}_{12} \mathrm{O}$ & - & $0.237 \pm 0.031$ & $0.083 \pm 0.005$ \\
\hline 19 & 22.71 & Octanal & $\mathrm{C}_{8} \mathrm{H}_{16} \mathrm{O}$ & $9.314 \pm 0.211$ & $6.789 \pm 0.308$ & $5.525 \pm 0.241$ \\
\hline 25 & 27.2 & Nonanal & $\mathrm{C}_{9} \mathrm{H}_{18} \mathrm{O}$ & $16.562 \pm 0.484$ & $12.268 \pm 0.240$ & $9.359 \pm 0.261$ \\
\hline 30 & 30.79 & (E)-2-Nonenal & $\mathrm{C}_{9} \mathrm{H}_{16} \mathrm{O}$ & $0.136 \pm 0.011$ & $0.936 \pm 0.092$ & $0.361 \pm 0.015$ \\
\hline 32 & 31.32 & cis-4-Decenal & $\mathrm{C}_{10} \mathrm{H}_{18} \mathrm{O}$ & $0.203 \pm 0.020$ & $0.242 \pm 0.033$ & - \\
\hline 33 & 31.68 & 3-Ethyl-Benzaldehyde & $\mathrm{C}_{9} \mathrm{H}_{10} \mathrm{O}$ & $0.144 \pm 0.010$ & $0.279 \pm 0.017$ & $0.164 \pm 0.015$ \\
\hline 37 & 34.92 & (E)-2-Decenal & $\mathrm{C}_{10} \mathrm{H}_{18} \mathrm{O}$ & $0.239 \pm 0.040$ & $0.480 \pm 0.035$ & $0.178 \pm 0.013$ \\
\hline 39 & 37.43 & 4-(1-Methylethyl)-1-Cyclohexene-1-Carboxaldehyde & $\mathrm{C}_{10} \mathrm{H}_{16} \mathrm{O}$ & $0.319 \pm 0.028$ & $0.319 \pm 0.027$ & $0.479 \pm 0.029$ \\
\hline 41 & 38.82 & 2-Dodecenal & $\mathrm{C}_{12} \mathrm{H}_{22} \mathrm{O}$ & - & $0.275 \pm 0.014$ & $0.166 \pm 0.016$ \\
\hline 49 & 46.3 & Undecanal & $\mathrm{C}_{11} \mathrm{H}_{22} \mathrm{O}$ & $0.291 \pm 0.015$ & $0.439 \pm 0.039$ & $0.284 \pm 0.009$ \\
\hline 51 & 49.53 & Pentadecanal & $\mathrm{C}_{15} \mathrm{H}_{30} \mathrm{O}$ & $0.271 \pm 0.012$ & $0.456 \pm 0.044$ & $0.356 \pm 0.054$ \\
\hline \multirow[t]{3}{*}{53} & 52.95 & Tetradecanal & $\mathrm{C}_{14} \mathrm{H}_{28} \mathrm{O}$ & $1.364 \pm 0.041$ & $1.266 \pm 0.047$ & $1.163 \pm 0.068$ \\
\hline & & Subtotal (GC peak area) & & $52.231 \pm 0.152$ & $49.631 \pm 0.098$ & $31.247 \pm 0.084$ \\
\hline & & Subtotal compounds number & & 14 & 15 & 14 \\
\hline \multicolumn{7}{|c|}{ Alcohols } \\
\hline 7 & 13.05 & 1-Pentanol & $\mathrm{C}_{5} \mathrm{H}_{12} \mathrm{O}$ & $0.998 \pm 0.074$ & $0.992 \pm 0.064$ & $0.585 \pm 0.027$ \\
\hline 9 & 17.42 & 1-Hexanol & $\mathrm{C}_{6} \mathrm{H}_{14} \mathrm{O}$ & $0.560 \pm 0.031$ & $0.509 \pm 0.075$ & $0.445 \pm 0.050$ \\
\hline 17 & 22.06 & 1-Octen-3-ol & $\mathrm{C}_{8} \mathrm{H}_{16} \mathrm{O}$ & $8.447 \pm 0.318$ & $8.448 \pm 0.400$ & $6.360 \pm 0.309$ \\
\hline 21 & 25.2 & 2,4-Dimethyl-Cyclohexanol & $\mathrm{C}_{8} \mathrm{H}_{16} \mathrm{O}$ & - & $0.143 \pm 0.008$ & $0.108 \pm 0.016$ \\
\hline 22 & 26.34 & 1-Octanol & $\mathrm{C}_{8} \mathrm{H}_{18} \mathrm{O}$ & $1.464 \pm 0.072$ & $2.373 \pm 0.182$ & $1.191 \pm 0.119$ \\
\hline 23 & 26.67 & (E)-2-Octen-1-ol & $\mathrm{C}_{8} \mathrm{H}_{16} \mathrm{O}$ & $0.986 \pm 0.063$ & $1.637 \pm 0.086$ & $0.941 \pm 0.092$ \\
\hline 29 & 29.07 & 6-Undecanol & $\mathrm{C}_{11} \mathrm{H}_{24} \mathrm{O}$ & $0.205 \pm 0.028$ & $0.263 \pm 0.034$ & $0.134 \pm 0.017$ \\
\hline 36 & 33.75 & 6,10,13-Trimethyltetradecanol & $\mathrm{C}_{17} \mathrm{H}_{36} \mathrm{O}$ & $0.154 \pm 0.012$ & $0.191 \pm 0.022$ & $0.229 \pm 0.039$ \\
\hline 40 & 38.46 & 1-[2-Methyl-3-(methylthio)allyl]- Cyclohex-2-enol & $\mathrm{C}_{11} \mathrm{H}_{18} \mathrm{OS}$ & $1.190 \pm 0.101$ & $1.210 \pm 0.087$ & $2.478 \pm 0.163$ \\
\hline 42 & 39.02 & 2-Hexyl-1-Decanol & $\mathrm{C}_{16} \mathrm{H}_{34} \mathrm{O}$ & $0.467 \pm 0.040$ & $0.500 \pm 0.033$ & $0.440 \pm 0.026$ \\
\hline \multirow[t]{3}{*}{43} & 39.16 & 1-(2-Nitropropyl)-Cyclohexanol & $\mathrm{C}_{9} \mathrm{H}_{17} \mathrm{NO}_{3}$ & $6.418 \pm 0.144$ & $6.292 \pm 0.175$ & $13.349 \pm 0.239$ \\
\hline & & Subtotal (GC peak area) & & $20.890 \pm 0.090$ & $22.558 \pm 0.113$ & $26.260 \pm 0.099$ \\
\hline & & Subtotal compounds number & & 10 & 11 & 11 \\
\hline
\end{tabular}


Table 2. Volatile compounds of muscle longissimus dorsi from veal fed different diets ${ }^{\text {a }}$ (Continued)

\begin{tabular}{|c|c|c|c|c|c|c|}
\hline \multirow{2}{*}{$\begin{array}{c}\text { Peak } \\
n\end{array}$} & \multirow{2}{*}{$\begin{array}{l}\mathrm{RT}^{\mathrm{b}} \\
(\mathrm{min})\end{array}$} & \multirow{2}{*}{ Compounds } & \multirow{2}{*}{$\begin{array}{l}\text { Molecular } \\
\text { formula }\end{array}$} & \multicolumn{3}{|c|}{ "GC peak area $(\%)^{\mathrm{c}} \pm \mathrm{RSD}^{\mathrm{d}}$} \\
\hline & & & & A & $\mathrm{B}$ & $\mathrm{C}$ \\
\hline \multicolumn{7}{|c|}{ Hydrocarbons } \\
\hline 4 & 10.22 & Octane & $\mathrm{C}_{8} \mathrm{H}_{18}$ & $0.631 \pm 0.037$ & $0.151 \pm 0.011$ & - \\
\hline 5 & 11.06 & Toluene & $\mathrm{C}_{7} \mathrm{H}_{8}$ & $0.284 \pm 0.023$ & $0.154 \pm 0.012$ & $0.182 \pm 0.010$ \\
\hline 13 & 18.57 & Decane & $\mathrm{C}_{10} \mathrm{H}_{22}$ & $0.162 \pm 0.029$ & $0.112 \pm 0.011$ & - \\
\hline 20 & 23.32 & 1,2,4-Trimethyl-Cyclohexane & $\mathrm{C}_{9} \mathrm{H}_{18}$ & - & $0.133 \pm 0.004$ & - \\
\hline 26 & 27.35 & Dodecane & $\mathrm{C}_{12} \mathrm{H}_{26}$ & $1.769 \pm 0.026$ & $1.902 \pm 0.109$ & $2.461 \pm 0.206$ \\
\hline 27 & 27.58 & 1,2-Dipentylcyclopropene & $\mathrm{C}_{13} \mathrm{H}_{24}$ & $0.886 \pm 0.067$ & $0.777 \pm 0.033$ & $0.518 \pm 0.010$ \\
\hline 34 & 32.31 & Hexyl-Benzene & $\mathrm{C}_{12} \mathrm{H}_{18}$ & $0.348 \pm 0.036$ & $0.445 \pm 0.048$ & $0.790 \pm 0.064$ \\
\hline 38 & 35.34 & Tetradecane & $\mathrm{C}_{14} \mathrm{H}_{30}$ & $1.216 \pm 0.018$ & $1.514 \pm 0.030$ & $2.169 \pm 0.163$ \\
\hline \multirow[t]{3}{*}{50} & 46.95 & 1,11-Tridecadiene & $\mathrm{C}_{13} \mathrm{H}_{24}$ & - & - & $0.062 \pm 0.005$ \\
\hline & & Subtotal (GC peak area) & & $5.296 \pm 0.019$ & $5.188 \pm 0.037$ & $6.182 \pm 0.075$ \\
\hline & & Subtotal compounds number & & 7 & 8 & 6 \\
\hline \multicolumn{7}{|c|}{ Others } \\
\hline 2 & 8.21 & o-Methylisourea hydrogen sulfate & $\mathrm{C}_{2} \mathrm{H}_{6} \mathrm{~N}_{2} \mathrm{O}$ & $2.808 \pm 0.063$ & $2.773 \pm 0.045$ & $1.889 \pm 0.124$ \\
\hline 14 & 20.21 & 2-Pentyl-Furan & $\mathrm{C}_{9} \mathrm{H}_{14} \mathrm{O}$ & $2.851 \pm 0.093$ & $5.090 \pm 0.129$ & $2.168 \pm 0.162$ \\
\hline 16 & 21.99 & n-Caproic acid vinyl ester & $\mathrm{C}_{8} \mathrm{H}_{14} \mathrm{O}_{2}$ & $0.179 \pm 0.014$ & $0.195 \pm 0.027$ & - \\
\hline 28 & 28.98 & Hexanoic acid, anhydride & $\mathrm{C}_{12} \mathrm{H}_{22} \mathrm{O}_{3}$ & $0.167 \pm 0.009$ & $0.198 \pm 0.033$ & $0.230 \pm 0.041$ \\
\hline 35 & 32.77 & 4-(1,1-Dimethylethyl)-2-Methyl-Phenol & $\mathrm{C}_{11} \mathrm{H}_{16} \mathrm{O}$ & $0.158 \pm 0.009$ & $0.323 \pm 0.031$ & $0.113 \pm 0.025$ \\
\hline 45 & 42.38 & 1,2-Benzenedicarboxylic acid & $\mathrm{C}_{8} \mathrm{H}_{6} \mathrm{O}_{4}$ & $3.268 \pm 0.109$ & $3.663 \pm 0.217$ & $3.794 \pm 0.197$ \\
\hline 47 & 42.87 & Butylated Hydroxytoluene & $\mathrm{C}_{15} \mathrm{H}_{24} \mathrm{O}$ & $0.825 \pm 0.033$ & $1.120 \pm 0.088$ & $1.923 \pm 0.042$ \\
\hline 48 & 45.32 & 2,5-bis(1,1-Dimethylethyl)-Phenol & $\mathrm{C}_{14} \mathrm{H}_{22} \mathrm{O}$ & $0.290 \pm 0.012$ & $0.342 \pm 0.035$ & $0.687 \pm 0.037$ \\
\hline \multirow[t]{3}{*}{54} & 64.92 & N-butyl-Benzenesulfonamide & $\mathrm{C}_{10} \mathrm{H}_{15} \mathrm{NO}_{2} \mathrm{~S}$ & - & $1.916 \pm 0.090$ & - \\
\hline & & Subtotal (GC peak area) & & $10.545 \pm 0.043$ & $15.62 \pm 0.067$ & $10.805 \pm 0.077$ \\
\hline & & Subtotal compounds number & & 8 & 9 & 7 \\
\hline
\end{tabular}

${ }^{a}$ Whole milk feeding group (A); quantitative feeding group of whole milk and calf starter diet (B); ad libitum feeding group of whole milk and calf starter diet (C).

${ }^{\mathrm{b}}$ Retention times (min).

${ }^{\mathrm{c}}$ Mean of five replicates (\%).

${ }^{\mathrm{d}}$ Relative standard deviation.

to discern the presence of inherent similarities in spectral profiles (Rivas-Cañedo et al., 2009). The results are displayed as score plots indicating the scatter of the samplessimilar volatile compositions are clustered together and different compositions are dispersed. In the PCA scores, each point represents an individual sample, and further composition differences are indicated by the PCA loading plots. Therefore, PCA offers a clear visual representation of the differences among the samples. It shows clear separation among the groups $\left(R^{2} X=0.909, Q^{2}=0.871 ;\right.$ Fig. 1$)$. $\mathrm{R}^{2} \mathrm{X}$ and $\mathrm{Q}^{2}$ expressed matrix of $\mathrm{X}$ explained and predictive ability of matrix model established, respectively. Their values were closer to 1 that showed the model was more reliable. Here samples A1-A5 clustered together similar to B1-B5 and C1-C5. There were some compounds that did not definitely belong in groups $\mathrm{A}, \mathrm{B}$, or $\mathrm{C}$ while others did. The scatter $3 \mathrm{D}$ plot shows a clear discrimination between group A, group B, and group C (Fig. 2).

Next, PLS-DA was performed to reduce the possible contribution of intergroup variability and to further imp- rove the separation between the samples. The PLS-DA analysis calculates models that differentiate groups or classes and among compounds. In the PLS-DA model, the samples from the different groups were sorted into different classes using score plots, and the compounds that contribute to the classification were identified in loading plots. These showed the importance of each variable to the classification. Each score plot has a loading plot associated with it, which makes it possible to identify the spectral regions (compounds) that are responsible for the observed sample clustering. The biplots (score plot and loading plot; Fig. 3) showed a clear differentiation between the groups $\left(R^{2} Y=0.995, Q^{2}=0.992\right)$, and the scatter 3D plot showed a clear discrimination between controls (Fig. 4). $R^{2} Y$ and $Q^{2}$ expressed matrix of $Y$ explained and predictive ability of matrix model established, respectively. Their values were closer to 1 that showed the model was more reliable. The VIP parameter was essentially a measure of the degree to which a particular variable explained the $\mathrm{Y}$ variance. 


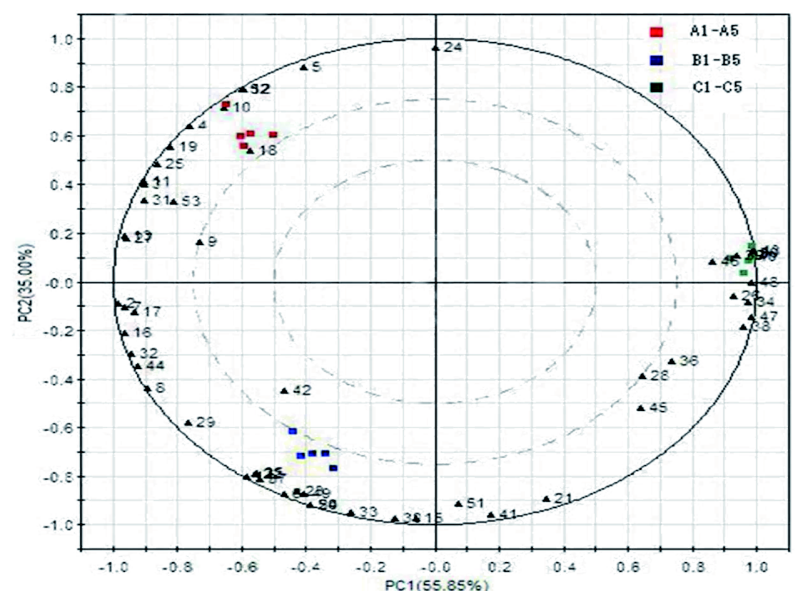

Fig. 1. PCA biplot (score plot and loading plot, PC1 $\times$ PC2) of the GC-MS peak area $(\%)$ of volatiles identified in veal (attribution of the peak number shown in Table 2). A1-A5: whole milk feeding group (A); B1-B5: quantitative feeding group of whole milk and calf starter diet (B); C1-C5: ad libitum feeding group of whole milk and calf starter diet (C).

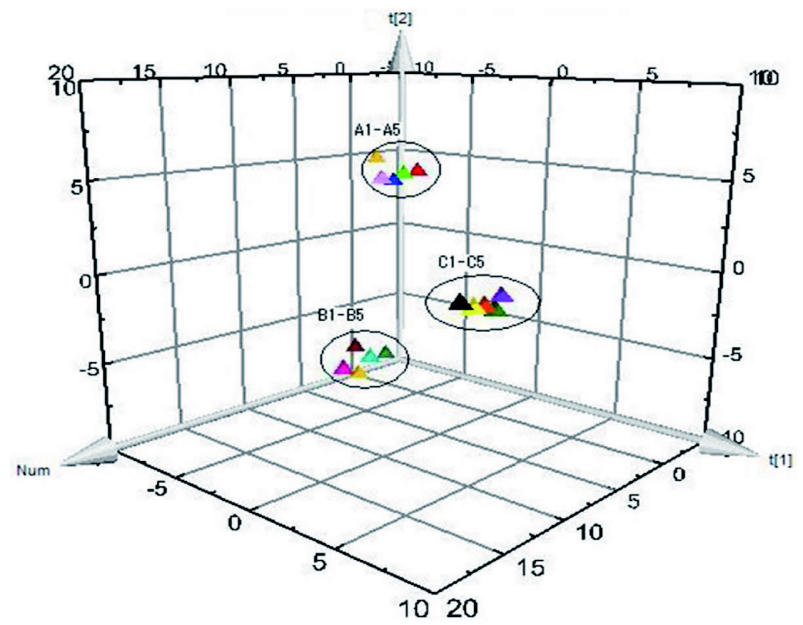

Fig. 2. PCA scatter 3D plot. The colors were correlated back to the samples shown in Table 1. A1-A5: whole milk feeding group (A); B1-B5: quantitative feeding group of whole milk and calf starter diet (B); C1-C5: ad libitum feeding group of whole milk and calf starter diet (C). $\mathrm{t}[1]$ : PC1(55.85\%), t[2]: PC2(35.00\%), Num: quintuplicate for each group.

According to results obtained by PCA and PLS-DA, the group A was mainly characterized by the presence of 2-heptanone, butylidene-1(3H)-isobenzofuranone and octane. Moreover, these carbonyl compounds when present at concentration above their odour threshold could contribute with fruity, sweet and flowery notes. (E)-2-decenal, 1-octanol and 2-pentyl-furan were the important fla-

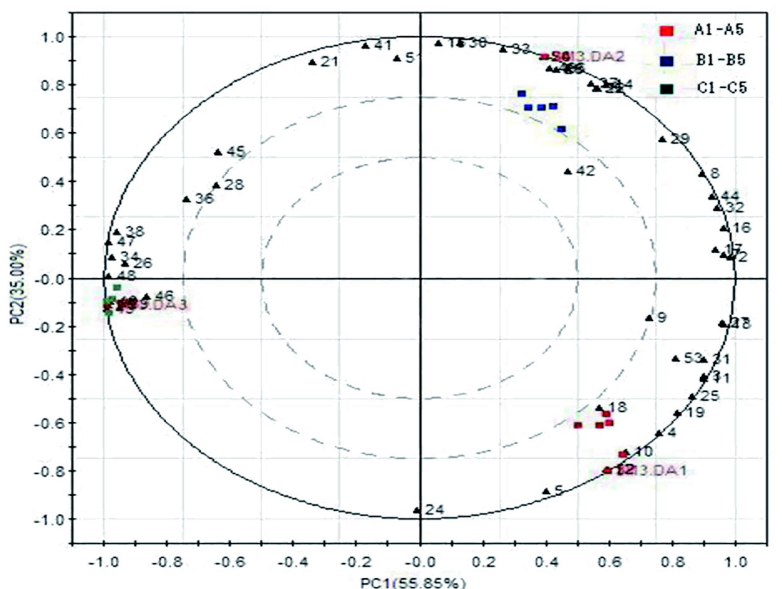

Fig. 3. PLS-DA biplot (score plot and loading plot, PC1 $\times$ PC2) of GC-MS peak area (\%) of volatile identified in veal (attribution of the peak number shown in Table 2). A1A5: whole milk feeding group (A); B1-B5: quantitative feeding group of whole milk and calf starter diet (B); C1C5: ad libitum feeding group of whole milk and calf starter $\operatorname{diet}(\mathrm{C})$.

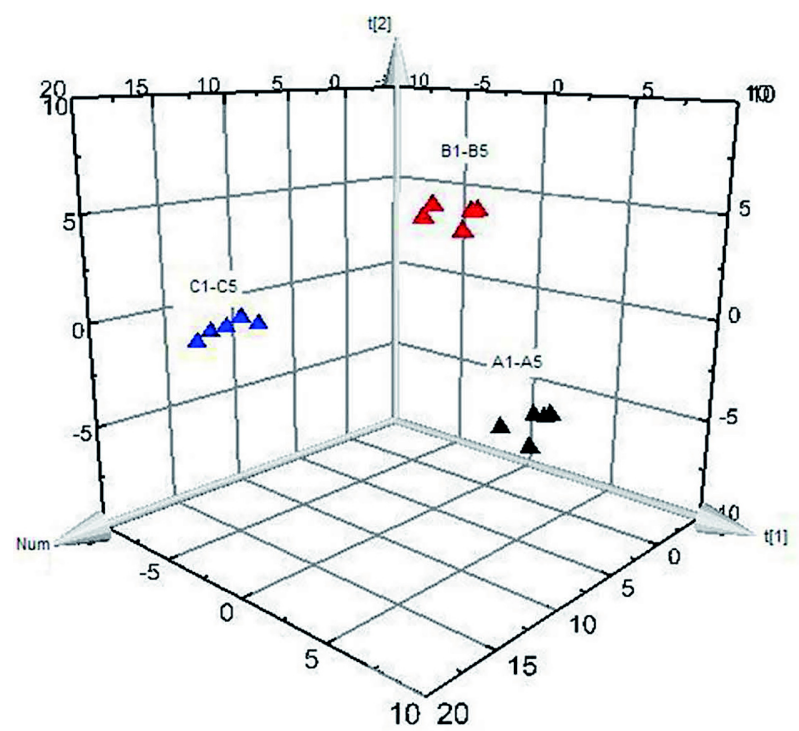

Fig. 4. PLS-DA scatter 3D plot. A1-A5: whole milk feeding group (A); B1-B5: quantitative feeding group of whole milk and calf starter diet (B); C1-C5: ad libitum feeding group of whole milk and calf starter diet (C). t[1]: PC1 $(55.85 \%), t[2]$ : PC2 (35.00\%), Num: quintuplicate for each group.

vor compounds in group B. For group C, 2,5-bis(1,1-dimethylethyl)-phenol, hexyl-benzene and 1-(2-nitropropyl)cyclohexanol were the main flavor substances. The flavors were dissimilar because of the different flavor substances in three groups.

Twenty three volatile compounds showed significance 
through VIP values (VIP $>1$ ) (Table 3 ) including 10 aldehydes, 4 ketones, 3 alcohols, 3 hydrocarbons and 3 others. Carbonyl compounds were quantitatively the largest group contributed most for flavor in veal. Of these, fifteen were common to the 3 groups. 2-dodecenal, (E)-2-heptenal, 2,4-dimethyl-cyclohexanol did not exist in group A. (E)2-heptenal, 1,2,4-trimethyl-cyclohexane, n-butyl-benzenesulfonamide were only in group B, and (Z)- 4-heptenal, 3-butylidene-1 $(3 \mathrm{H})$-isobenzofuranone occurred in group A, only. This multivariate statistical analysis showed a clear distinction among the 3 kinds of veal (Table 3 ).

The volatile compounds detected in the three groups could be produced by two ways-one consisting of volatile components produced by Maillard reactions and the other consisting of volatile components formed through lipid oxidation. The higher peak area values for the products of lipid oxidation could be ascribed to the mild cooking conditions $\left(60^{\circ} \mathrm{C}\right)$, employed in this study. More severe cooking conditions were needed to produce more Maillard reactions products, which are more aromatic than lipid oxidation products (Xu et al., 2008).

Aldehydes have low detection thresholds and small amounts can exert an outsize influence on odor (Liu et al., 2004). Certain volatile aldehydes such as heptanal, (Z)-octanal, and nonanal are formed by oxidation of oleic acid. These volatiles are very important, because they have been found to impart a pleasant sweet and fruity odor to the meat, while heptanal is associated with the odor of potatoes. It reported that oxidation at high temperatures resulted in ketone and alcohol formation (Tan et al., 2004). They are related to sweet odor notes. Aromatic hydrocarbons played an important role in the overall flavor of meat, even though none is individually responsible for meat odor (Min et al., 1979). In addition, two sulfur compounds (N-butyl-benzenesulfonamide, 1-[2-Methyl-3-(methylthio) allyl]-cyclohex-2-enol) were identified. Sulfur compounds are important flavor substances with odor thresholds (Wu et al., 2001). They were very important contributors to the flavor profile of cooked meat.

\section{Conclusion}

The composition of volatile flavor substances differs between the three veal groups; this may be due to the dif-

Table 3. The volatile compounds contributed most by VIP values (VIP > 1)

\begin{tabular}{|c|c|c|c|c|c|}
\hline \multirow{2}{*}{$\begin{array}{c}\text { peak } \\
n\end{array}$} & \multirow{2}{*}{ Compounds } & \multicolumn{3}{|c|}{$\mathrm{GC}_{\text {peak area }(\%)}{ }^{\mathrm{a}} \pm \mathrm{RSD}^{\mathrm{b}}$} & \multirow{2}{*}{$\mathrm{VIP}^{\mathrm{c}}$} \\
\hline & & A & B & $\mathrm{C}$ & \\
\hline 41 & 2-Dodecenal & - & $0.275 \pm 0.014^{*}$ & $0.166 \pm 0.016^{*}$ & 1.1833 \\
\hline 30 & (E)-2-Nonenal & $0.136 \pm 0.011^{*}$ & $0.936 \pm 0.0928^{*}$ & $0.361 \pm 0.015^{*}$ & 1.1804 \\
\hline 15 & (E)-2-Heptenal & - & $0.237 \pm 0.031^{*}$ & $0.083 \pm 0.005^{*}$ & 1.1794 \\
\hline 20 & 1,2,4-Trimethyl-Cyclohexane & - & $0.133 \pm 0.004^{*}$ & - & 1.1606 \\
\hline 54 & N-butyl-Benzenesulfonamide & - & $1.916 \pm 0.090^{*}$ & - & 1.1597 \\
\hline 24 & 2-Nonanone & $0.641 \pm 0.070 *$ & $0.282 \pm 0.015^{*}$ & $0.498 \pm 0.010^{*}$ & 1.1596 \\
\hline 33 & 3-Ethyl-Benzaldehyde & $0.144 \pm 0.010^{*}$ & $0.279 \pm 0.017^{*}$ & $0.164 \pm 0.015^{*}$ & 1.1545 \\
\hline 21 & 2,4-Dimethyl-Cyclohexanol & - & $0.143 \pm 0.008 *$ & $0.108 \pm 0.016^{*}$ & 1.1526 \\
\hline 6 & 3-Hydroxy-2-Butanone & $0.295 \pm 0.007^{*}$ & $0.583 \pm 0.027^{*}$ & $0.262 \pm 0.0280^{*}$ & 1.1329 \\
\hline 23 & (E)-2-Octen-1-ol & $0.986 \pm 0.063$ & $1.637 \pm 0.086^{*}$ & $0.941 \pm 0.092$ & 1.1221 \\
\hline 5 & Toluene & $0.284 \pm 0.023^{*}$ & $0.154 \pm 0.012^{*}$ & $0.182 \pm 0.010^{*}$ & 1.1200 \\
\hline 14 & 2-pentyl-furan & $2.851 \pm 0.093^{*}$ & $5.090 \pm 0.129^{*}$ & $2.168 \pm 0.162 *$ & 1.1117 \\
\hline 52 & butylidene-1(3H)-isobenzofuranone & $0.271 \pm 0.031^{*}$ & - & - & $1.1 \mathrm{M} 58$ \\
\hline 49 & undecanal & $0.291 \pm 0.015$ & $0.439 \pm 0.039^{*}$ & $0.284 \pm 0.009$ & 1.1018 \\
\hline 37 & (E)-2-decenal & $0.239 \pm 0.040^{*}$ & $0.480 \pm 0.035^{*}$ & $0.178 \pm 0.013^{*}$ & 1.0989 \\
\hline 35 & 4-(1,1-dimethylethyl)-2-methyl-Phenol & $0.158 \pm 0.009 *$ & $0.323 \pm 0.031 *$ & $0.113 \pm 0.025^{*}$ & 1.0924 \\
\hline 12 & (Z)-4-heptenal & $0.150 \pm 0.029^{*}$ & - & - & 1.0899 \\
\hline 22 & 1-octanol & $1.464 \pm 0.072 *$ & $2.373 \pm 0.182 *$ & $1.191 \pm 0.119^{*}$ & 1.0879 \\
\hline 51 & pentadecanal & $0.271 \pm 0.012 *$ & $0.456 \pm 0.044^{*}$ & $0.356 \pm 0.054^{*}$ & 1.0752 \\
\hline 4 & octane & $0.631 \pm 0.037^{*}$ & $0.151 \pm 0.011 *$ & - & 1.0558 \\
\hline 10 & 2-heptanone & $0.878 \pm 0.069^{*}$ & $0.577 \pm 0.012$ & $0.539 \pm 0.031$ & 1.0545 \\
\hline 19 & octanal & $9.314 \pm 0.211 *$ & $6.789 \pm 0.308^{*}$ & $5.525 \pm 0.241 *$ & 1.0228 \\
\hline 25 & nonanal & $16.562 \pm 0.484 *$ & $12.268 \pm 0.240^{*}$ & $9.359 \pm 0.261^{*}$ & 1.0098 \\
\hline
\end{tabular}

${ }^{a}$ Mean of five replicates (\%).

${ }^{b}$ Relative standard deviation.

${ }^{\mathrm{c}}$ The parameters of the variable importance in the projection.

*The mean difference is significant according to Fisher's protected LSD test, at a $p$ value of 0.05 . 
ferent diets. It showed similar result with Resconi et al. (2010) and Vasta et al. (2011). Our preliminary data suggested that the main flavor components of veal including (E)-2-nonenal, (E)-2-heptenal, 1,2,4-trimethyl-cyclohexane, N-butyl-benzenesulfonamide, 2-nonanone, 3-ethylbenzaldehyde, 2,4-dimethyl-cyclohexanol, 3-hydroxy-2-butanone, (E)-2-octen-1-ol,toluene, 2-pentyl-furan, 3-butylidene-1(3H)-isobenzofuranone, undecanal, (E)-2-decenal, 4-(1,1-dimethylethyl)-2-methyl-Phenol, (Z)-4-heptenal, 1octanol, pentadecanal, octane, 2-heptanone, octanal, and nonanal.

Our study has improved the understanding of the influence of the finishing diet on the volatile components contained in veal and contributes to the development of diets for veal that meet consumer expectations in different markets. It also provided a scientific reference for the future production of high-quality veal. However, the study of volatile substances of veal is still in its infancy. Further research using gas chromatography-olfactometry (GC-O) is needed for confirmation of our results.

\section{Acknowledgements}

This project was funded by the National Key Technology R\&D Program (2007BAD52B05), Gansu Key Lab Construction Program (085RTSA004) and the Innovation Fund Project of Gansu Agricultural University. The authors also gratefully acknowledge the team of the Gansu Key Laboratory of Herbivorous Animal Biotechnology for sample manufacture.

\section{References}

1. Brennand, C. P. and Lindsay, R. C. (1992) Distribution of volatile branched-chain fatty acids in various lamb tissues. Meat Sci. 31, 411-421.

2. Calkins, C. R. and Hodgen, J. M. (2007) A fresh look at meat flavor. Meat Sci. 77, 63-80.

3. Gasser, U. and Grosch, W. (1988) Identification of volatile flavour compounds with high aroma values from cooked beef. Z. Lebensm. Unters. Forsch. 186, 489-494.

4. Gorraiz, C., Beriain, M. J., Chasco, J., and Insausti, K. (2002) Effect of aging time on volatile compounds, odor, and flavor of cooked beef from pirenaica and friesian bulls and heifers. J. Food Sci. 67, 916-922.

5. Guth, H. and Grosch, W. (1994) Identification of the character impact odorants of stewed beef juice by instrumental analyses and sensory studies. J. Agric. Food Chem. 42, 28622866.

6. Insausti, K., Goñi, V., Petri, E., Gorraiz, C., and Beriain, M. J. (2005) Effect of weight at slaughter on the volatile compo- unds of cooked beef from Spanish cattle breeds. Meat Sci. 70, 3-90.

7. Koutsidis, G., Elmore, J. S., Oruna-Concha, M. J., Campo, M. M., Wood, J. D., and Mottram, D. S. (2008a) Water-soluble precursors of beef flavour. Meat Sci. 79, 270-277.

8. Koutsidis, G., Elmore, J. S., Oruna-Concha, M. J., Campo, M. M., Wood, J. D., and Mottram, D. S. (2008b) Water-soluble precursors of beef flavour. Part II: Effect of post-mortem conditioning. Meat Sci. 79, 124-130.

9. Lee, K. H., Yun, H., Lee, J. W., Ahn, D. U., Lee, E. J., and Jo, C. (2012) Volatile compounds and odor preferences of ground beef added with garlic and red wine, and irradiated with charcoal pack. Radiat. Phys. Chem. 81, 1103-1106.

10. Liu, Y., Xu, X. L., and Zhou, G. H. (2004) Report of flavor for Nanjing soysauce beef. Jiangsu Agric. Sci. 5, 101-104.

11. Mao, J. W. and Xu, H. Z. (2011) Influence factors on young white beef and industrial development. China Cattle Sci. 37, 56-58.

12. Min, D. B. S., Ina, K., Peterson, R. J., and Chang, S. S. (1979) Preliminary identification of volatile flavor compounds in the neutral fraction of roast beef. J. Food Sci. 44, 639-642.

13. Moon, S. Y., Margaret, A. C., Eunice, C. Y., and Li, C. (2006) Odour-active components of simulated beef flavour analysed by solid phase microextraction and gas chromatography-mass spectrometry-olfactometry. Food Res. Int. 39, 294-308.

14. Qi, Y. M., Sun, B. G., Huang, M. Q., Liu, Y. P., and Chen, H. T. (2010) Analysis of volatile compounds in Yueshengzhai spiced beef by simultaneous distillation extraction and gas chromatography-mass spectrometry. Food Sci. 31, 370-374.

15. Rivas-Cañedo, A., Fernández-García, E., and Nuñez, M. (2009) Volatile compounds in fresh meats subjected to high pressure processing: Effect of the packaging material. Meat Sci. 81, 321-328.

16. Resconi, V. C., Campo, M. M., Montossi, F., Ferreira, V., Sañudo, C., and Escudero, A. (2010) Relationship between odour-active compounds and flavour perception in meat from lambs fed different diets. Meat Sci. 85, 700-706.

17. Robbins, K., Jensen, J., Ryan, K. J., Homco-Ryan, C., McKeith, F. K., and Brewer, M. S. (2003a) Effects of dietary vitamin E supplementation on textual and aroma attributes of enhanced beef clod roasts in a cook/hot-hold situation. Meat Sci. 65, 317-322.

18. Robbins, K., Jensen, J., Ryan, K. J., Homco-Ryan, C., McKeith, F. K., and Brewer, M. S. (2003b) Consumer attitudes towards beef and acceptability of enhanced beef. Meat Sci. 65, 721-729.

19. Ruiz, J., Cava, R., Ventanas, J., and Jensen, M. (1998) Headspace solid phase microextraction for the analysis of volatiles in a meat product dry cured Iberian ham. J. Agric. Food Chem. 46, 4688-4694.

20. Shi, X. X., Yu, Q. L., and Tian, J. C. (2011) Changes in main volatile compounds during aging process of Yak meat. Transactions of the Chinese Society for Agric. Machinery 42, 144147.

21. Stetzer, A. J., Cadwallader, K., Singh, T. K., Mckeith, F. K., and Brewer, M. S. (2008) Effect of enhancement and ageing 
on flavor and volatile compounds in various beef muscles. Meat Sci. 79, 13-19.

22. Tan, B. and Ding, X. X. (2004) Flavor compounds-A review. China Food Addit. 6, 73-79.

23. Varavinit, S., Shobsngob, S., Bhidyachakorawat, M., and Suphantharik, M. (2000) Production of meat-like flavor. Sci. Asia 26, 219-224.

24. Vasta, V., Luciano, G., Dimauro, C., Röhrle, F., Priolo, A., Monahan, F. J., and Moloney, A. P. (2011) The volatile profile of longissimus dorsi muscle of heifers fed pasture, pasture silage or cereal concentrate. Meat Sci. 87, 282-289.

25. Vasta, V., Ratel, J., and Engel, E. (2007) Mass spectrometry analysis of volatile compounds in raw meat for the authentication of the feeding background of farm animals. J. Agric. Food Chem. 55, 4630-4639.

26. Wang, C. T., Jiang, Y. M., Li, P., and Han, L. (2006) Determination of flavor substances in the meat of Tianzhu white yak by SPME coupled to GC-MS. J. Gansu Agric. Univ. 41, 118121.

27. Watkins, P. J., Rose, G., Warner, R. D., Dunshea, F. R., and Pe- thick, D. W. (2012) A comparison of solid-phase microextraction (SPME) with simultaneous distillation-extraction (SDE) for the analysis of volatile compounds in heated beef and sheep fats. Meat Sci. 91, 99-107.

28. Wei, J. M., Luo, Y. Z., Wang, J. Q., Shi, X. X., Liu, X., Hu, J., Chen, S. R., and Li, S. B. (2011) Analysis of odors from veal by solid phase microextraction-gas chromatography. Sci. Tech. Food Ind. 32, 73-75.

29. Wilkes, J. G., Conte, E. D., Kim, Y. K., Holcomb, M., Sutherland, J. B., and Miller, D. W. (2000) Sample preparation for the analysis of flavors and off-flavors in foods. J. Chromatogr. $A$ 880, 3-33.

30. $\mathrm{Wu}, \mathrm{H}$. and $\mathrm{Xu}, \mathrm{S}$. Y. (2001) Volatile aroma components in beef flavoring. J. Wuxi Univ. Light Ind. 20, 158-163.

31. Xu, H. G., Liu, X., Zhao, J., and Gao, Y. X. (2008) Effects of ribose to cysteine ratios on the formation of volatile compounds from the Maillard reaction in supercritical carbon dioxide. Food Res. Int. 41, 730-737.

(Received 2014.5.7/Revised 2014.9.22/Accepted 2014.9.23) 